\title{
Chronic Kidney Disease Has a Graded Association with Death and Cardiovascular Outcomes in Stable Coronary Artery Disease: An Analysis of 21,911 Patients from the CLARIFY Registry
}

\author{
Emmanuelle Vidal-Petiot ${ }^{1,2,3}{ }^{\text {D }}$, Nicola Greenlaw ${ }^{4}$, Paul R. Kalra ${ }^{5}$, Xavier Garcia-Moll ${ }^{6}$, \\ Jean-Claude Tardif ${ }^{7}$, Ian Ford ${ }^{4}$, Jose Zamorano ${ }^{8}$, Roberto Ferrari ${ }^{9,10}$, Michal Tendera ${ }^{11}(\mathbb{D}$, \\ Kim M. Fox ${ }^{12}$, Philippe Gabriel Steg ${ }^{1,12,13, * \mathbb{D}}$ and on behalf of the CLARIFY investigators ${ }^{\dagger}$ \\ 1 Université de Paris, Paris, France; emmanuelle.vidal-petiot@aphp.fr \\ 2 Physiology Department, Assistance Publique-Hôpitaux de Paris, Hôpital Bichat, 75018 Paris, France \\ 3 Institut nationale de la santé et de la recherché médicale (INSERM) U1149, Centre de Recherche sur \\ l'Inflammation, 75018 Paris, France \\ 4 Robertson Centre for Biostatistics, University of Glasgow, Glasgow G12 8QQ, UK; \\ Nicola.Greenlaw@glasgow.ac.uk (N.G.); Ian.Ford@glasgow.ac.uk (I.F.) \\ 5 Portsmouth Hospitals NHS Trust, Portsmouth PO6 3LY, UK; paulkalra@doctors.org.uk \\ 6 Hospital Santa Creu i Sant Pau, 08041 Barcelona, Spain; XGarcia-Moll@santpau.cat \\ 7 Montreal Heart Institute, Université de Montreal, Montreal, QC H1T1C8, Canada; \\ Jean-Claude.Tardif@icm-mhi.org \\ 8 University Hospital Ramon y Cajal, 28040 Madrid, Spain; zamorano@secardiologia.es \\ 9 Centro Cardiologico Universitario di Ferrara, University of Ferrara, 44124 Cona, FE, Italy; \\ roberto.ferrari@unife.it \\ 10 Maria Cecilia Hospital, GVM Care \& Research, 48033 Cotignola, RA, Italy \\ 11 Department of Cardiology and Structural Heart Disease, School of Medicine in Katowice, \\ Medical University of Silesia, 40-055 Katowice, Poland; michal.tendera@gmail.com \\ 12 National Heart and Lung Institute, Imperial College, Royal Brompton Hospital, London SW3 6NP, UK; \\ kim.fox@imperial.ac.uk \\ 13 Cardiology Department, Assistance Publique-Hôpitaux de Paris, Hôpital Bichat, French Alliance for \\ Cardiovascular Trials, INSERM U1148, 75018 Paris, France \\ * Correspondence: gabriel.steg@aphp.fr; Tel.: +331-40-25-86-68; Fax: +331-40-25-88-65 \\ + A list of the CLARIFY Investigators is included in the Supplement.
}

Received: 1 November 2019; Accepted: 13 December 2019; Published: 18 December 2019

\begin{abstract}
Chronic kidney disease (CKD) is associated with an increased cardiovascular risk in a broad spectrum of populations. However, the risk associated with a reduced estimated glomerular filtration rate (eGFR) in patients with stable coronary artery disease receiving standard care in the modern era, independently of baseline cardiovascular disease, risk factors, and comorbidities, remains unclear. We analyzed data from 21,911 patients with stable coronary artery disease, enrolled in 45 countries between November 2009 and July 2010 in the CLARIFY registry. Patients with abnormal renal function were older, with more comorbidities, and received slightly lower-although overall high—rates of evidence-based secondary prevention therapies than patients with normal renal function. The event rate of patients with CKD stage $3 \mathrm{~b}$ or more (eGFR $<45 \mathrm{~mL} / \mathrm{min} / 1.73 \mathrm{~m}^{2}$ ) was much higher than that associated with any comorbid condition. In a multivariable adjusted Cox proportional hazards model, lower eGFR was independently associated with a graded increased risk of cardiovascular mortality, with adjusted HRs (95\% CI) of 0.98 (0.81-1.18), 1.31 (1.05-1.63), 1.77 (1.38-2.27), and 3.12 (2.25-4.33) for eGFR $60-89,45-59,30-44$, and $<30 \mathrm{~mL} / \mathrm{min} / 1.73 \mathrm{~m}^{2}$, compared with eGFR $\geq 90 \mathrm{~mL} / \mathrm{min} / 1.73 \mathrm{~m}^{2}$. A strong graded independent relationship exists between the degree of CKD and cardiovascular mortality in this large cohort of patients with chronic coronary artery disease, despite high rates of
\end{abstract}


secondary prevention therapies. Among clinical risk factors and comorbid conditions, CKD stage 3b or more is associated with the highest cardiovascular mortality.

Keywords: chronic kidney disease; chronic coronary artery disease; CLARIFY registry

\section{Introduction}

Chronic kidney disease (CKD) is a well-recognized risk factor for mortality and cardiovascular disease. This increased risk has been noted in general population cohorts [1-5], in cohorts at high risk for, or with established, cardiovascular disease [4,6] and in patients with heart failure [7]. However, few data are available in the specific population of patients with stable coronary artery disease, especially in a contemporary cohort including patients largely treated with drugs associated with prognostic benefit [8] and without severe heart failure at inclusion.

We used data from the global prospective observational longitudinal registry of patients with chronic coronary artery disease (CLARIFY) to compare the risk associated with different stages of CKD with that associated with other risk factors and comorbid conditions. In addition, we assessed whether reduced renal function is a risk factor, independent of other established risk factors and comorbidities, in patients with chronic coronary artery disease treated according to standard care in the modern era.

\section{Methods}

\subsection{Study Design and Participants}

Clarify is an international, prospective, observational, longitudinal registry of outpatients with chronic coronary artery disease (ISRCTN43070564; www.clarifyregistry.com). The study rationale and methods have been published elsewhere [9,10]. Briefly; 32,703 patients were enrolled in 45 countries in Africa, Asia, Australia, Europe, the Middle East, and North, Central, and South America between November 2009 and June 2010. Eligible patients had chronic coronary artery disease proven by a history of at least one of the following: Documented myocardial infarction more than three months before enrolment; angiographic demonstration of coronary stenosis of more than $50 \%$; chest pain with evidence of myocardial ischemia (stress electrocardiogram, stress echocardiograph, or myocardial perfusion imaging); or coronary artery bypass graft or percutaneous coronary intervention performed more than three months before enrolment. These criteria were not mutually exclusive. Exclusion criteria were hospital admission for cardiovascular reasons (including revascularization) in the past 3 months; planned revascularization; conditions hampering participation over 5-year follow-up, such as limited cooperation, inability to provide informed consent, serious non-cardiovascular disease, or conditions interfering with life expectancy (e.g., cancer; drug abuse); or other severe cardiovascular diseases such as advanced heart failure, severe valve disease, or history of valve repair or replacement. CKD, per se, was not an exclusion criterion. To ensure that the study population was representative of chronic coronary artery disease outpatients, recruitment of sites and subjects was based on a predefined selection of physicians (cardiologists as well as office-based primary care physicians and physicians based in hospitals with outpatient clinics) by national coordinators, using the best available epidemiological data in each country reflecting the burden of coronary artery disease; this was done in an attempt to provide a distribution of physicians across regions and locations (i.e., urban; suburban; or rural areas), mimicking the epidemiological patterns in each country. In each practice; patient recruitment was restricted over a brief period to achieve near-consecutive patient enrolment in order to avoid selection bias. The study was conducted in accordance with the principles in the Declaration of Helsinki and local ethical approval was obtained in all countries prior to recruitment. All patients gave written informed consent before any data acquisition was performed. The study was registered at ISRCTN as ISRCTN43070564. 


\subsection{Data Collection}

The investigators completed standardized case report forms at baseline and at a yearly patient visit (plus or minus three months) for up to 5 years. In addition, telephone contact with the patient, a designated relative or contact, or their physician was attempted in the 6-month interim between the yearly visits. At each yearly visit, symptoms, clinical examination, results of the main recent clinical and biological tests, treatment, and clinical outcomes were recorded. Patients were treated according to usual clinical practice at each institution, with no specific tests or therapies defined in the study protocol. Where applicable, registries could be used to retrieve the vital status. Events were accepted as reported by physicians and were not adjudicated. Events were accepted as reported by physicians following the detailed requirement of the case reports forms and were not adjudicated. However, to ensure data quality, onsite monitoring visits were carried out in $5 \%$ of randomly selected centres with source verification of all events and of $100 \%$ of the collected data, centralized verification of the electronic case report forms were performed for completeness, consistency, and accuracy, and regular telephone contacts with investigators were done to limit missing data and loss to follow-up.

Baseline estimated glomerular filtration rate (eGFR) was derived from the creatinine-derived chronic kidney disease Epidemiology Collaboration (CKD-EPI) equation [11], and analyzed in five categories: $<30,30-44,45-59,60-89$, and $\geq 90 \mathrm{~mL} / \mathrm{min} / 1.73 \mathrm{~m}^{2}$, the latter being used as reference. Analyses were also conducted using eGFR as a continuous variable, with values above $90 \mathrm{~mL} / \mathrm{min} / 1.73 \mathrm{~m}^{2}$ truncated at this threshold. Results were provided per 5 unit decrease in eGFR below this threshold and scaled at $90 \mathrm{~mL} / \mathrm{min} / 1.73 \mathrm{~m}^{2}$.

A flow diagram of the study population is shown in eFigure in the Supplementary Materials; 325 patients had an incomplete 5-year follow-up, 10,407 patients had incomplete sets of variables required to calculate eGFR (mainly ethnicity, which local ethics committees did not authorize collecting in France and Portugal, and creatinine values), and patients with baseline eGFR below $10 \mathrm{~mL} / \mathrm{min} / 1.73 \mathrm{~m}^{2}(n=60)$ were excluded, leaving a total of 21,911 patients in the present analysis.

\subsection{Study Outcomes}

Pre-specified outcomes of interest were cardiovascular death (primary outcome), all-cause death, myocardial infarction (fatal or not), stroke (fatal or not), and hospital admission for heart failure (secondary outcomes). Cardiovascular death was defined as death from myocardial infarction or stroke, any sudden death including unobserved and unexpected death (while sleeping) unless proven otherwise by autopsy, death ascribed to heart failure, death following cardiac or vascular procedure/operation, death due to ruptured aneurysm or pulmonary embolism, death due to amputation (except for trauma or malignancy), and death that could not be definitely ascribed to non-cardiovascular death.

\subsection{Statistical Analysis}

Continuous variables were presented as mean \pm standard deviation or median (interquartile range), depending on the distribution of the data; categorical data were presented as count and percentage. Comparisons between eGFR categories were performed using one-way ANOVA, or Kruskal-Wallis test for continuous variables as appropriate and Chi-Squared tests for categorical data.

Event rates and corresponding 95\% confidence intervals (CI) for the primary outcome and each of the secondary outcomes were provided per 1000 patient-years, using the date of event or censoring date. If multiple events were recorded, the event rate was calculated using the date of first event.

Cox proportional hazards models were used to assess the association between eGFR, in categories or as a continuous variable, and outcomes. In addition to crude hazard ratios (HRs), adjusted HRs were estimated after adjustment for potential confounding factors, selected a priori as potential confounders, namely age, sex, geographical region, smoking status, diabetes, body-mass index, treated hypertension, baseline systolic blood pressure, low-density and high-density lipoprotein cholesterol levels, previous myocardial infarction, previous percutaneous coronary intervention, previous coronary artery bypass 
grafting, number of diseased coronary vessels at baseline, peripheral artery disease at baseline, previous stroke or transient ischemic attack, previous hospital admission for (or symptoms of) heart failure, left ventricular ejection fraction, atrial fibrillation or flutter, and baseline drugs (any antiplatelet, statins, angiotensin-converting enzyme inhibitors, angiotensin-receptor blockers, and beta-blockers).

Data were analyzed as recorded without imputation for missing data. Adjustment variables were analyzed including a category for missing data to minimize the loss of data in the analysis.

Interaction between eGFR and diabetes, treated hypertension, and age ( $<$ or $\geq 60$ years) were tested for the categorical and continuous analyses of eGFR.

The statistical analysis was done with SAS (version 9.3).

\section{Results}

A total of 21,911 patients with chronic coronary artery disease and available baseline eGFR were included in the analysis. Baseline characteristics of the patients, in the total study population and by category of baseline eGFR, are reported in Table 1. Mean age was $63.9 \pm 10.4$ years, 16,941 (77\%) were men, 15,731 (72\%) had treated hypertension, $6646(30 \%)$ had diabetes, and $2788(13 \%)$ and 10,261 (47\%) were current and former smokers, respectively. Mean eGFR was $76 \pm 19 \mathrm{~mL} / \mathrm{min} / 1.73 \mathrm{~m}^{2}$. 
Table 1. Demographic and baseline characteristics of the patients, for the total population $(n=21,911)$ and by estimated glomerular filtration rate (eGFR) subgroup.

\begin{tabular}{|c|c|c|c|c|c|c|c|c|}
\hline \multirow{3}{*}{ Parameter } & \multirow{3}{*}{$\begin{array}{l}\text { Number of } \\
\text { Patients }\end{array}$} & \multirow{2}{*}{ Total Population } & \multicolumn{5}{|c|}{ GFR Subgroups (in $\mathrm{mL} / \mathrm{min} / 1.73 \mathrm{~m}^{2}$ ) } & \multirow{3}{*}{$p$-Value } \\
\hline & & & $<30$ & $30-44$ & $45-60$ & $60-89$ & $\geq \mathbf{9 0}$ & \\
\hline & & $(n=21,911)$ & $(n=233)$ & $(n=1166)$ & $(n=3347)$ & $(n=11,693)$ & $(n=5472)$ & \\
\hline Age (years) & 21,911 & $63.9(10.4)$ & $73.1(9.5)$ & $71.9(9.0)$ & $69.84(8.7)$ & $64.7(9.5)$ & $56.5(8.8)$ & $<0.0001$ \\
\hline Men & 21,911 & $16,941(77.3)$ & $141(60.5)$ & $735(63.0)$ & 2254 (67.3) & $9223(78.9)$ & $4588(83.9)$ & $<0.0001$ \\
\hline Body Mass Index $\left(\mathrm{kg} / \mathrm{m}^{2}\right)$ & 21,897 & $27.5[24.9,30.5]$ & $27.2[24.2,30.8]$ & $27.6[24.8,30.9]$ & $27.5[24.9,30.6]$ & $27.4[25,30.4]$ & $27.5[24.9,30.8]$ & 0.2438 \\
\hline Diabetes & 21,909 & $6646(30.3)$ & $131(56.2)$ & $521(44.7)$ & $1143(34.2)$ & $3231(27.6)$ & $1620(29.6)$ & $<0.0001$ \\
\hline Smoking status & 21,911 & & & & & & & \\
\hline Current & - & $2788(12.7)$ & $14(6.0)$ & $69(5.9)$ & $248(7.4)$ & $1431(12.2)$ & $1026(18.8)$ & $<0.0001$ \\
\hline Former & - & $10,261(46.8)$ & $112(48.1)$ & $508(43.6)$ & $1486(44.4)$ & $5612(48.0)$ & $2543(46.5)$ & - \\
\hline Never & - & $8862(40.4)$ & $107(45.9)$ & $589(50.5)$ & $1613(48.2)$ & 4650 (39.8) & $1903(34.8)$ & - \\
\hline Treated hypertension & 21,910 & $15,731(71.8)$ & $211(90.6)$ & $984(84.4)$ & $2621(78.3)$ & $8332(71.26)$ & $3583(65.5)$ & $<0.0001$ \\
\hline Systolic blood pressure (mm Hg) & 21,908 & $131(17)$ & $133(20)$ & $133(18)$ & $133(18)$ & $131(17)$ & $129(16)$ & $<0.0001$ \\
\hline Diastolic blood pressure $(\mathrm{mm} \mathrm{Hg})$ & 21,908 & $77(10)$ & $74(12)$ & $76(11)$ & $77(10)$ & $77(10)$ & $78(10)$ & $<0.0001$ \\
\hline Heart Rate (beats/minute) & 21,910 & $69(11)$ & $70(12.3)$ & $69(12)$ & $69(11)$ & $68(11)$ & $69(11)$ & $<0.0001$ \\
\hline Myocardial Infarction & 21,911 & $13,550(61.8)$ & $136(58.4)$ & $735(63.0)$ & $1987(59.4)$ & $7187(61.5)$ & $3505(64.05)$ & 0.0001 \\
\hline Percutaneous coronary intervention & 21,911 & $12,389(56.5)$ & $108(46.34)$ & $579(49.7)$ & $1700(50.8)$ & $6549(56.0)$ & $3453(63.1)$ & $<0.0001$ \\
\hline Coronary artery bypass graft surgery & 21,911 & $5298(24.2)$ & $89(38.2)$ & $328(28.1)$ & $967(28.9)$ & $2880(24.6)$ & 1034 (18.9) & $<0.0001$ \\
\hline Peripheral artery disease & 21,909 & $2095(9.6)$ & $44(18.9)$ & $180(15.4)$ & $418(12.5)$ & $1065(9.1)$ & $388(7.1)$ & $<0.0001$ \\
\hline Transient Ischemic Attack & 21,910 & $679(3.1)$ & $10(4.3)$ & $75(6.4)$ & $176(5.3)$ & $306(2.6)$ & $112(2.05)$ & $<0.0001$ \\
\hline Stroke & 21,910 & $940(4.3)$ & $26(11.2)$ & $105(9.0)$ & $202(6.0)$ & $481(4.1)$ & $126(2.3)$ & $<0.0001$ \\
\hline Atrial fibrillation/Flutter & 21,911 & $1582(7.2)$ & 34 (14.6) & $157(13.5)$ & $379(11.3)$ & $831(7.1)$ & $181(3.3)$ & $<0.0001$ \\
\hline Hospitalization for heart failure & 21,911 & $1104(5.00)$ & $48(20.6)$ & $143(12.3)$ & $236(7.1)$ & $504(4.3)$ & $173(3.2)$ & $<0.0001$ \\
\hline Symptoms of heart failure & 21,911 & & & & & & & \\
\hline None & - & $18,348(83.7)$ & $184(79.0)$ & $915(78.5)$ & $2700(80.7)$ & $9861(84.3)$ & $4688(85.67)$ & $<0.0001$ \\
\hline NYHA Class II & - & 2969 (13.6) & 37 (15.9) & $201(17.2)$ & 514 (15.4) & 1557 (13.3) & $660(12.06)$ & - \\
\hline NYHA Class III & - & $594(2.7)$ & $12(5.2)$ & $50(4.3)$ & $133(4.0)$ & $275(2.4)$ & $124(2.27)$ & - \\
\hline Left Ventricular Ejection Fraction (\%) & 15,731 & $55.6(11.2)$ & $49.3(14.6)$ & $52.3(12.6)$ & $54.8(11.8)$ & $56.1(10.9)$ & $56.03(10.44)$ & $<0.0001$ \\
\hline $\operatorname{HbA1C}(\%)$ & 6638 & $6.84(1.82)$ & $7.24(1.67)$ & $7.09(1.54)$ & $6.92(2.69)$ & $6.74(1.6)$ & $6.89(1.6)$ & $<0.0001$ \\
\hline Creatinine $(\mathrm{mmol} / \mathrm{L})$ & 21,911 & $0.088[0.076,0.101]$ & $0.198[0.186,0.226]$ & $0.141[0.125,0.156]$ & $0.112[0.1,0.122]$ & $0.088[0.08,0.097]$ & $0.071[0.062,0.079]$ & $<0.0001$ \\
\hline eGFR $\left(\mathrm{mL} / \mathrm{min} / 1.73 \mathrm{~m}^{2}\right)$ & 21,911 & $76(19)$ & $25(4)$ & $39(4)$ & $54(4)$ & $76(9)$ & $99(7)$ & - \\
\hline Total Cholesterol $(\mathrm{mmol} / \mathrm{L})$ & 20,843 & $4.3[3.6,5]$ & $4.2[3.6,4.9]$ & $4.2[3.5,5]$ & $4.3[3.6,5.1]$ & $4.3[3.7,5]$ & $4.2[3.6,5]$ & 0.0027 \\
\hline HDL-cholesterol (mmol/L) & 18,513 & $1.1[1.0,1.4]$ & $1.0[0.9,1.3]$ & $1.1[0.9,1.3]$ & $1.1[1.0,1.4]$ & $1.1[1.0,1.4]$ & $1.1[0.9,1.3]$ & $<0.0001$ \\
\hline LDL-cholesterol (mmol/L) & 17,505 & $2.3[1.9,2.9]$ & $2.3[1.7,2.9]$ & $2.2[1.8,2.8]$ & $2.3[1.9,2.9]$ & $2.4[1.9,3.0]$ & $2.4[1.9,3.0]$ & 0.0024 \\
\hline Fasting Triglycerides $(\mathrm{mmol} / \mathrm{L})$ & 19,262 & $1.4[1.0,2.0]$ & $1.6[1.1,2.0]$ & $1.5[1.1,2.1]$ & $1.5[1.1,2.0]$ & $1.4[1.0,1.9]$ & $1.4[1.0,2.0]$ & $<0.0001$ \\
\hline \multicolumn{9}{|l|}{ Baseline medication } \\
\hline Aspirin & 21,910 & $19,560(89.3)$ & $180(77.3)$ & $947(81.2)$ & $2867(85.7)$ & $10,460(89.5)$ & $5106(93.3)$ & $<0.0001$ \\
\hline Thienopyridine & 21,902 & $5650(25.8)$ & $76(32.6)$ & $302(25.9)$ & $795(23.8)$ & 2855 & $1622(29.7)$ & $<0.0001$ \\
\hline Any antiplatelet agent & 21,911 & $20,895(95.4)$ & $207(88.8)$ & $1055(90.5)$ & 3118 (93.2) & 11,166 (95.5) & 5349 (97.8) & $<0.0001$ \\
\hline
\end{tabular}


Table 1. Cont.

\begin{tabular}{|c|c|c|c|c|c|c|c|c|}
\hline \multirow{3}{*}{ Parameter } & \multirow{3}{*}{$\begin{array}{l}\text { Number of } \\
\text { Patients }\end{array}$} & \multirow{2}{*}{ Total Population } & \multicolumn{5}{|c|}{ GFR Subgroups (in $\mathrm{mL} / \mathrm{min} / 1.73 \mathrm{~m}^{2}$ ) } & \multirow{3}{*}{$p$-Valu } \\
\hline & & & $<30$ & $30-44$ & $45-60$ & $60-89$ & $\geq \mathbf{9 0}$ & \\
\hline & & $(n=21,911)$ & $(n=233)$ & $(n=1166)$ & $(n=3347)$ & $(n=11,693)$ & $(n=5472)$ & \\
\hline Lipid-lowering drugs & 21,911 & $20,470(93.4)$ & $213(91.4)$ & $1081(92.7)$ & $3074(91.8)$ & $10,938(93.5)$ & 5164 (94.4) & $<0.0001$ \\
\hline Beta-Blockers & 21,910 & $16,625(75.9)$ & $168(72.1)$ & $893(76.6)$ & $2512(75.1)$ & $8766(75.0)$ & $4286(78.3)$ & $<0.0001$ \\
\hline Calcium antagonists & 21,909 & $5956(27.2)$ & $96(41.2)$ & $372(31.9)$ & $1065(31.8)$ & $3155(27.0)$ & $1268(23.2)$ & $<0.0001$ \\
\hline $\begin{array}{c}\text { Angiotensin-converting enzyme } \\
\text { inhibitors }\end{array}$ & 21,910 & $11,408(52.1)$ & $82(35.2)$ & $534(45.8)$ & $1692(50.6)$ & $6125(52.4)$ & $2975(54.4)$ & $<0.0001$ \\
\hline Angiotensin II receptor antagonists & 21,909 & $5873(26.8)$ & $90(38.6)$ & $445(38.2)$ & $1074(32.1)$ & $3067(26.2)$ & $1197(21.9)$ & $<0.0001$ \\
\hline Any renin-angiotensin system blocker & 21,910 & $16,843(76.9)$ & $164(70.4)$ & $929(79.7)$ & $2680(80.1)$ & $8975(76.8)$ & 4095 (74.9) & $<0.0001$ \\
\hline Diuretics & 21,910 & $6492(29.6)$ & $156(67.0)$ & $633(54.3)$ & $1380(41.2)$ & $3193(27.3)$ & $1130(20.7)$ & $<0.0001$ \\
\hline
\end{tabular}

Data are mean (SD), median (IQR), or number (\%). Some percentages do not add up to 100 because of rounding. eGFR = Glomerular Filtration Rate estimated from the CKD-EPI equation;
NYHA = New York Heart Association (NYHA) Functional Classification; HDL-cholesterol = high-density lipoprotein cholesterol; LDL-cholesterol = low-density lipoprotein cholesterol. 
Compared with patients with eGFR $\geq 90 \mathrm{~mL} / \mathrm{min} / 1.73 \mathrm{~m}^{2}$, those with a lower eGFR were older, more likely to be female, have diabetes and hypertension, and less likely to be current smokers. They were less likely to have undergone percutaneous coronary intervention, and more likely to have undergone coronary artery bypass grafting. They had a higher prevalence of peripheral artery disease, heart failure, previous stroke, and atrial fibrillation or flutter. They were less likely to receive antiplatelet agents, lipid lowering drugs, and angiotensin-converting enzyme inhibitors, but more likely to receive angiotensin II receptor blockers. The rate of prescription of any renin-angiotensin system blocker was lowest $(70.4 \%)$ in patients with eGFR $<30 \mathrm{~mL} / \mathrm{min} / 1.73 \mathrm{~m}^{2}$.

After a median follow-up of 5 years $(4.82 ; 5.10), 1837$ patients died (1158 of cardiovascular cause), 829 patients had a myocardial infarction (fatal or not), 493 had a stroke (fatal or not), and 1279 were hospitalized for heart failure.

The cumulative incidence of cardiovascular death increased with decreasing eGFR (Figure 1).

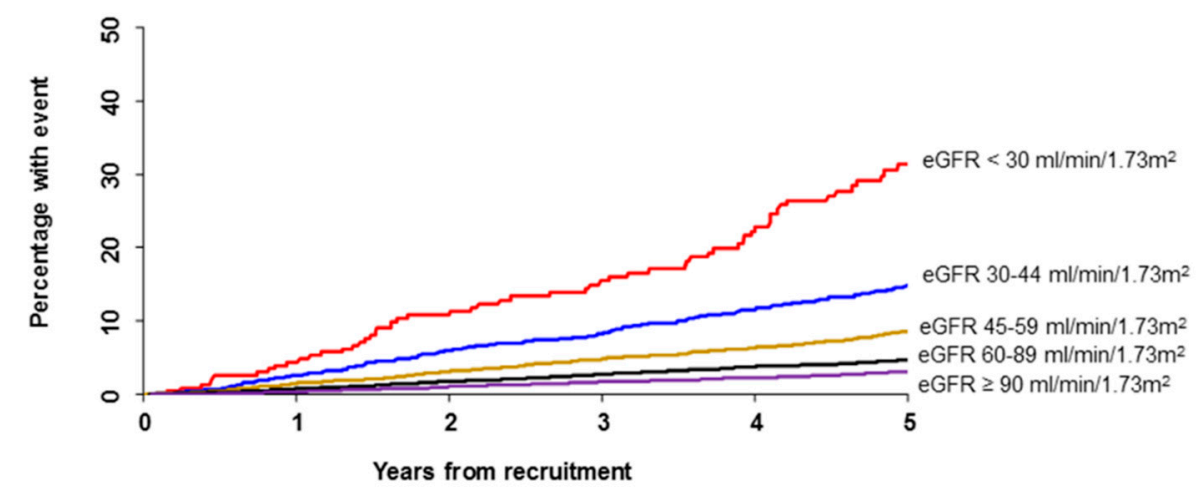

$\begin{array}{lrrrrrr}\text { No. at Risk } & & & & & & \\ \text { eGFR }<30 \mathrm{ml} / \mathrm{min} / 1.73 \mathrm{~m}^{2} & 233 & 214 & 182 & 159 & 132 & 70 \\ \text { eGFR } 30-44 \mathrm{ml} / \mathrm{min} / 1.73 \mathrm{~m}^{2} & 1166 & 1108 & 1028 & 935 & 843 & 523 \\ \text { eGFR } 45-59 \mathrm{ml} / \mathrm{min} / 1.73 \mathrm{~m}^{2} & 3347 & 3236 & 3078 & 2895 & 2724 & 1766 \\ \text { eGFR } 60-89 \mathrm{ml} / \mathrm{min} / 1.73 \mathrm{~m}^{2} & 11,693 & 11,407 & 10,892 & 10,334 & 9835 & 6485 \\ \text { eGFR } \geq 90 \mathrm{ml} / \mathrm{min} / 1.73 \mathrm{~m}^{2} & 5472 & 5358 & 5113 & 4863 & 4662 & 3001\end{array}$

Figure 1. Kaplan-Meier plots showing cumulative incidence of cardiovascular death by eGFR category.

Compared to major risk factors for coronary artery disease and prior cardiovascular history (such as previous myocardial infarction or heart failure), CKD stage $3 \mathrm{~b}$ or more was, by far, the one associated with the highest increase in the unadjusted risk of cardiovascular death (Figure 2). 


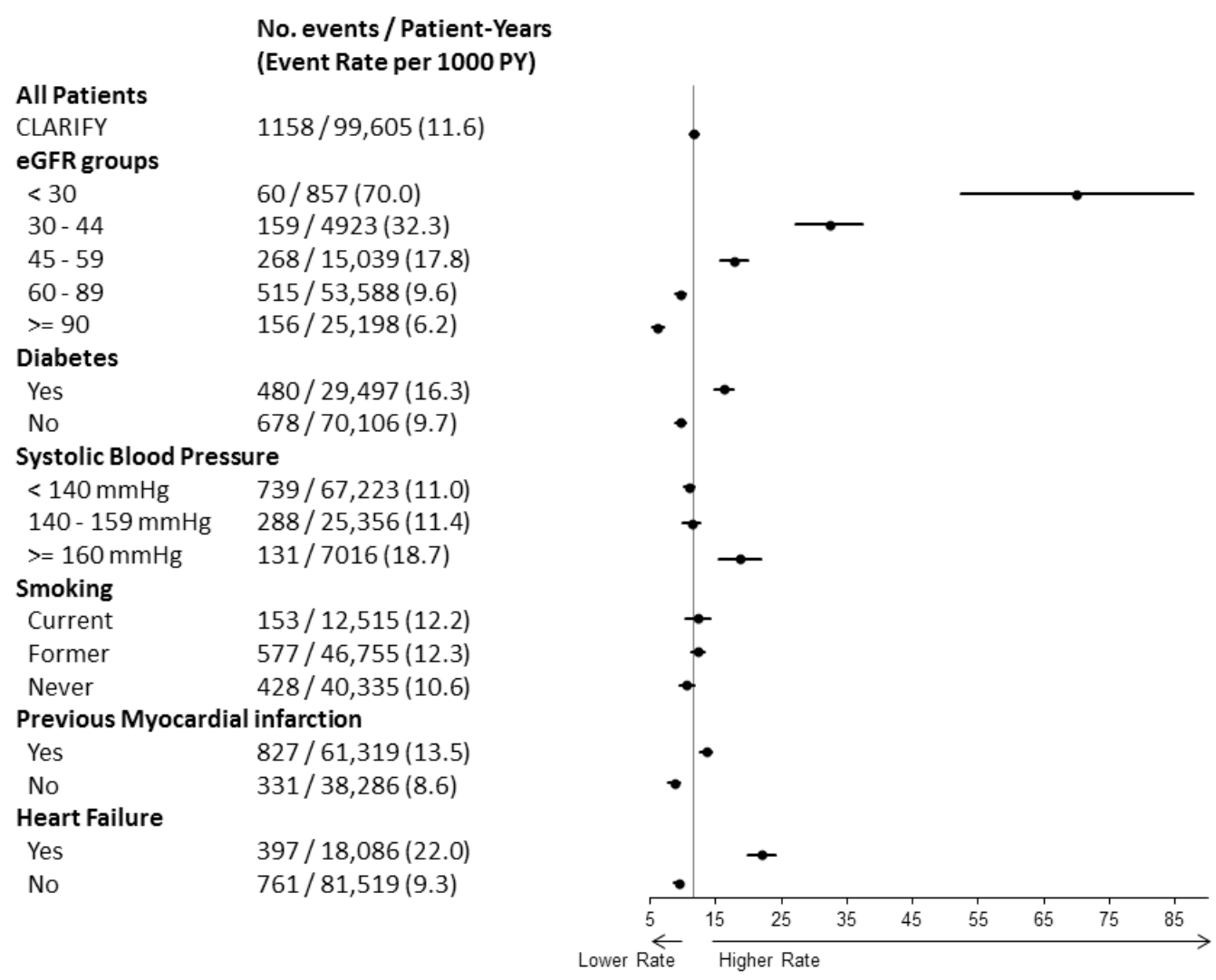

Figure 2. Event rates for cardiovascular death. Unadjusted rates (95\% CI) per 1000 patient-years for cardiovascular death are indicated in the total study population, by category of eGFR, diabetic status, systolic blood pressure level, smoking status, previous myocardial infarction, and history of heart failure.

Event rates, and crude and adjusted HRs for all outcomes, for each eGFR category, are reported in Table 2. Unadjusted rates of cardiovascular mortality were $6.2,9.6,17.8,32.3$, and 70.0 per 1000 patient-years in patients with eGFR $\geq 90,60-89,45-59,30-44$, and $<30 \mathrm{~mL} / \mathrm{min} / 1.73 \mathrm{~m}^{2}$. Even after multiple adjustments for baseline cardiovascular disease, risk factors, comorbidities, and drugs, a lower eGFR was associated with increased risk of cardiovascular death, with adjusted HRs (95\% CI) of 0.98 (0.81-1.18), 1.31 (1.05-1.63), 1.77 (1.38-2.27), and 3.12 (2.25-4.33), for eGFR 60-89, 45-59, $30-44$, and $<30 \mathrm{~mL} / \mathrm{min} / 1.73 \mathrm{~m}^{2}$, as compared with eGFR $\geq 90 \mathrm{~mL} / \mathrm{min} / 1.73 \mathrm{~m}^{2}$. The adjusted risk was also significantly increased as early as stage 3a CKD (eGFR $\left.45-59 \mathrm{~mL} / \mathrm{min} / 1.73 \mathrm{~m}^{2}\right)$ for all-cause death, with adjusted HRs (95\% CI) of 0.99 (0.85-1.15), 1.23 (1.03-1.46), 1.72 (1.41-2.10), and 2.96 (2.27-3.86) for eGFR $60-89,45-59,30-44$, and $<30 \mathrm{~mL} / \mathrm{min} / 1.73 \mathrm{~m}^{2}$, as compared with eGFR $\geq 90 \mathrm{~mL} / \mathrm{min} / 1.73 \mathrm{~m}^{2}$, and for admission for heart failure, with adjusted HRs (95\% CI) of 1.10 (0.93-1.29), 1.36 (1.12-1.66), 2.08 (1.65-2.63), and 2.11 (1.44-3.11) for eGFR 60-89, 45-59, 30-44, and $<30 \mathrm{~mL} / \mathrm{min} / 1.73 \mathrm{~m}^{2}$, as compared with eGFR $\geq 90 \mathrm{~mL} / \mathrm{min} / 1.73 \mathrm{~m}^{2}$. Although crude risk increased as eGFR decreased for myocardial infarction and stroke, adjusted HRs were only significantly increased for myocardial infarction when eGFR was below $30 \mathrm{~mL} / \mathrm{min} / 1.73 \mathrm{~m}^{2}$. 
Table 2. Event rates and crude and adjusted hazard ratios by GFR subgroups.

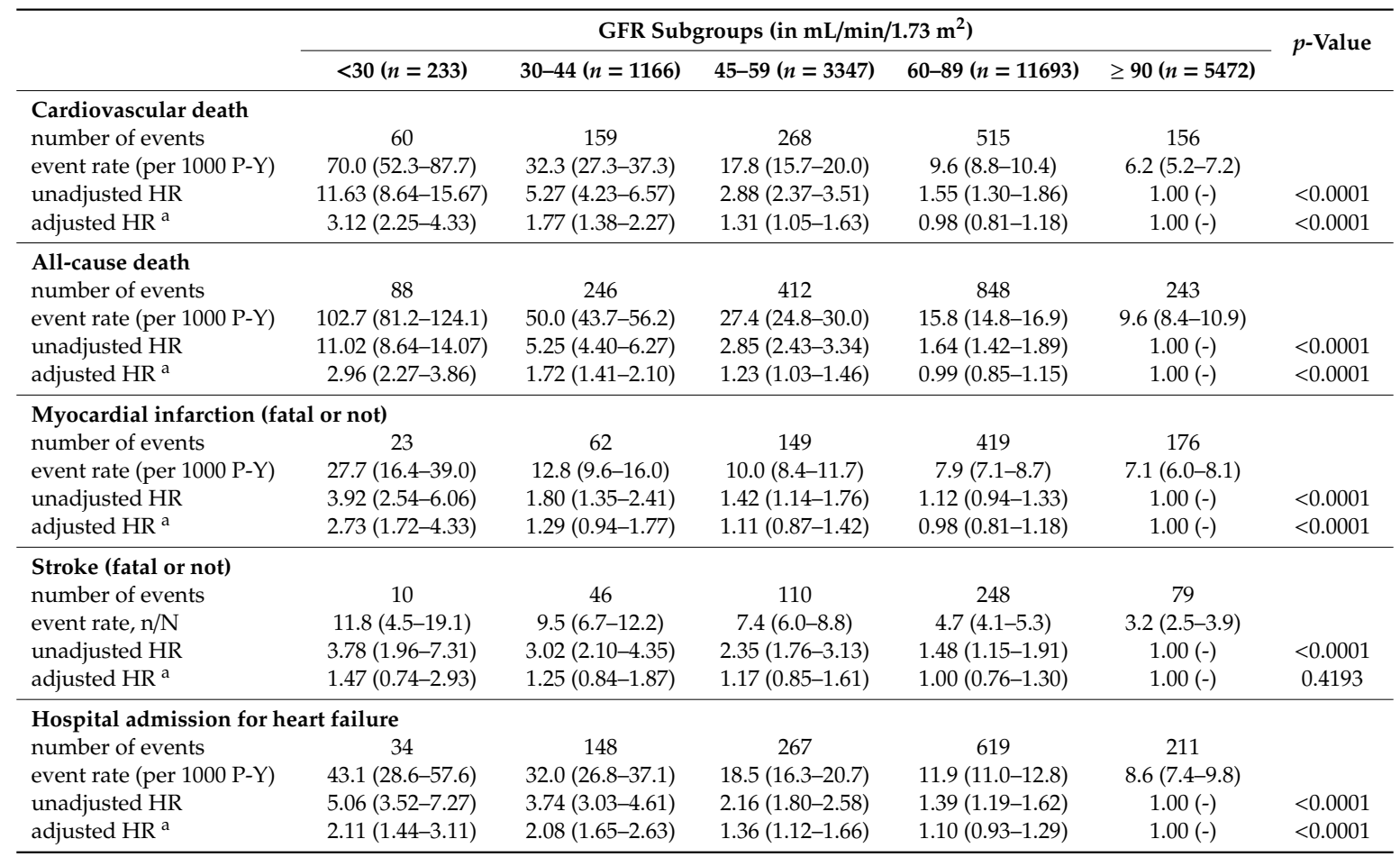

$\mathrm{P}-\mathrm{Y}=$ patient-years; $\mathrm{HR}=$ hazard ratio; $95 \% \mathrm{CI}=95 \%$ confidence interval. ${ }^{\text {a }}$ Adjusted for age, sex, geographical region, smoking status, diabetes, body-mass index, treated hypertension, baseline systolic blood pressure, low-density and high-density lipoprotein cholesterol levels, previous myocardial infarction, previous percutaneous coronary intervention, previous coronary artery bypass grafting, number of diseased coronary vessels at baseline, peripheral artery disease at baseline, previous stroke or transient ischemic attack, previous hospital admission for (or symptoms of) heart failure, left ventricular ejection fraction, atrial fibrillation or flutter, and baseline drugs (any antiplatelet, statins, angiotensin-converting enzyme inhibitors, angiotensin-receptor blockers, and beta-blockers).

When eGFR was analyzed as a continuous variable, worsening of eGFR below $90 \mathrm{~mL} / \mathrm{min} / 1.73 \mathrm{~m}^{2}$ was significantly associated with all outcomes, with adjusted HRs (95\% CI) of 1.079 (1.060-1.099), 1.073 (1.057-1.088), 1.029 (1.005-1.053), 1.033 (1.004-1.063), and 1.061 (1.042-1.080) for cardiovascular death, all-cause death, myocardial infarction, stroke, and hospital admission for heart failure, respectively (Table 3).

Table 3. Crude and adjusted hazard ratios per 5 units decrease in eGFR below $90 \mathrm{~mL} / \mathrm{min} / 1.73 \mathrm{~m}^{2}$.

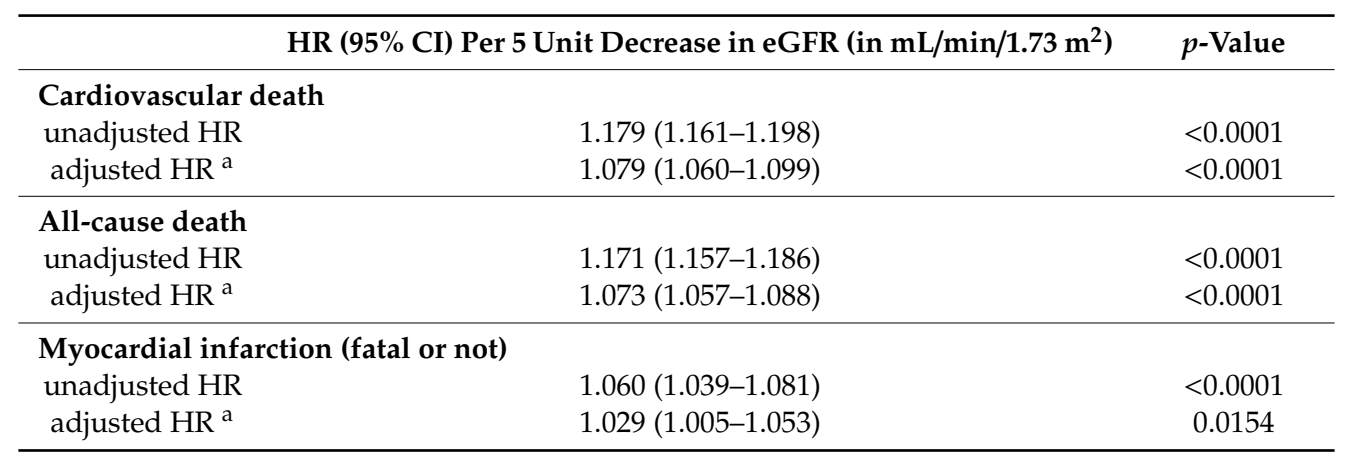


Table 3. Cont.

\begin{tabular}{|c|c|c|}
\hline & HR (95\% CI) Per 5 Unit Decrease in eGFR (in $\mathrm{mL} / \mathrm{min} / 1.73 \mathrm{~m}^{2}$ ) & $p$-Value \\
\hline \multicolumn{3}{|c|}{ Stroke (fatal or not) } \\
\hline unadjusted HR & $1.110(1.083-1.138)$ & $<0.0001$ \\
\hline adjusted $\mathrm{HR}^{\mathrm{a}}$ & $1.033(1.004-1.063)$ & 0.0273 \\
\hline \multicolumn{3}{|c|}{ Hopital admission for heart failure } \\
\hline $\begin{array}{l}\text { unadjusted } H R \\
\text { adjusted } \mathrm{HR}^{\mathrm{a}}\end{array}$ & $\begin{array}{l}1.124(1.107-1.142) \\
1.061(1.042-1.080)\end{array}$ & $\begin{array}{l}<0.0001 \\
<0.0001\end{array}$ \\
\hline
\end{tabular}

Values above $90 \mathrm{~mL} / \mathrm{min} / 1.73 \mathrm{~m}^{2}$ are truncated at this threshold. $\mathrm{HR}=$ hazard ratio; $95 \% \mathrm{CI}=95 \%$ confidence interval. a Adjusted for age, sex, geographical region, smoking status, diabetes, body-mass index, treated hypertension, baseline systolic blood pressure, low-density and high-density lipoprotein cholesterol levels, previous myocardial infarction, previous percutaneous coronary intervention, previous coronary artery bypass grafting, number of diseased coronary vessels at baseline, peripheral artery disease at baseline, previous stroke or transient ischemic attack, previous hospital admission for (or symptoms of) heart failure, left ventricular ejection fraction, atrial fibrillation or flutter, and baseline drugs (any antiplatelet, statins, angiotensin-converting enzyme inhibitors, angiotensin-receptor blockers, and beta-blockers).

Interaction analyses are presented in eTable in the Supplementary Materials. No significant interaction was found between CKD and diabetes, treated hypertension, or age when eGFR was analyzed in five categories. When eGFR was analyzed as a continuous variable, a significant interaction was observed between eGFR and history of hypertension. Indeed, a decreasing eGFR was associated with an increased risk of myocardial infarction and with an increased risk of stroke only in patients with hypertension ( $p$-values for interaction 0.0090 and 0.0313 for myocardial infarction and stroke, respectively).

\section{Discussion}

In this large international contemporary registry of patients with coronary artery disease, a reduced eGFR was associated with a gradual increase in the risks of mortality and adverse cardiovascular events. This increased risk appeared as early as CKD stage $3 a$ (eGFR $45-59 \mathrm{~mL} / \mathrm{min} / 1.73 \mathrm{~m}^{2}$ ) for both cardiovascular and total mortality, and persisted after multiple adjustments for potential confounding factors, including cardiovascular risk factors, overt cardiovascular disease at baseline, comorbidities, and medication. In addition, the large size of the cohort allowed us to reliably estimate the risks associated with CKD, compared to those associated with diabetes, elevated systolic blood pressure, smoking, and previous myocardial infarction or heart failure in patients with coronary artery disease treated in routine practice. CKD stage $3 \mathrm{~b}$ or more, as estimated from the CKD-EPI equation [11,12], was a marker of substantially increased risk in patients with coronary artery disease, far higher than that associated with all above-mentioned risk factors and conditions.

In the present analysis, the risk associated with eGFR $60-89 \mathrm{~mL} / \mathrm{min} / 1.73 \mathrm{~m}^{2} \mathrm{did}$ not differ from that associated with eGFR $\geq 90 \mathrm{~mL} / \mathrm{min} / 1.73 \mathrm{~m}^{2}$. Accordingly, for GFR values of $60 \mathrm{~mL} / \mathrm{min} / 1.73 \mathrm{~m}^{2}$ or more, the GFR value, per se, does not define CKD in the absence of markers of kidney damage such as albuminuria or morphological abnormalities [13].

Below $60 \mathrm{~mL} / \mathrm{min} / 1.73 \mathrm{~m}^{2}$, prior studies have generally shown an association between a lower eGFR and adverse cardiovascular outcomes and mortality [14], although data are not all consistent, especially regarding the threshold of eGFR below which risk increases.

In the REACH registry of patients at very high cardiovascular risk, Dumaine et al. found that severe CKD (as estimated by creatinine clearance below $30 \mathrm{~mL} / \mathrm{min} / 1.73 \mathrm{~m}^{2}$, hence a true GFR below this threshold) was associated in increased risks of mortality, myocardial infarction, and death, whereas no significantly increased risk was found above this value [6]. Similarly, several studies conducted in community-based cohorts found no significant association between moderate CKD and death or cardiovascular disease $[15,16]$. In contrast, in a meta-analysis of general population cohorts, Matsushita et al. found that mortality was unrelated to eGFR above $75 \mathrm{~mL} / \mathrm{min} / 1.73 \mathrm{~m}^{2}$, and increased below this value [3]. Likewise, in 15,582 subjects from the Atherosclerosis Risk in Communities (ARIC) study, 
an eGFR between 60 and $89 \mathrm{~mL} / \mathrm{min} / 1.73 \mathrm{~m}^{2}$ was associated with an increased risk of atherosclerotic cardiovascular disease compared with an eGFR of 90 to $150 \mathrm{~mL} / \mathrm{min} / 1.73 \mathrm{~m}^{2}$ [2].

As previously observed in numerous other studies [17], the magnitude of the risk associated with a lower eGFR diminished after adjustment, indicating that demographic and clinical characteristics of patients with CKD, including older age, higher blood pressure [18], and prior cardiovascular disease [19], contribute in part to the association between CKD and risks of death and cardiovascular disease. Comorbidities ought to be taken into account when assessing renal and cardiovascular risks of patients with CKD [20]. In addition, although overall rates of secondary prevention therapies were high in the CLARIFY population, patients with CKD received suboptimal treatment [8]. The proportion of patients receiving antiplatelets, lipid-lowering drugs, and beta-blockers decreased from $97.8 \%$ to $88.8 \%$, $94.4 \%$ to $91.4 \%$, and $78.3 \%$ to $72.1 \%$, respectively, in patients with eGFR $\geq 90$ compared with those with eGFR $<30 \mathrm{~mL} / \mathrm{min} / 1.73 \mathrm{~m}^{2}$. Patients with CKD stage 3 received the highest rate of renin-angiotensin system blockers ( $80.1 \%$ for CKD stage $3 a$ and $79.7 \%$ for CKD stage $3 b$ ), but this rate decreased to $70.4 \%$ in patients with eGFR $<30 \mathrm{~mL} / \mathrm{min} / 1.73 \mathrm{~m}^{2}$. In addition to the higher burden of comorbidities [20], suboptimal secondary prevention may contribute in part to the higher event rates observed with more advanced CKD [21-23].

However, a lower eGFR was still strongly associated with adverse outcomes after adjustment for risk factors, baseline cardiovascular disease, comorbidities, and medications. Multiple pathophysiological explanations have been proposed in favour of a causal link underlying the adverse cardiovascular profile of CKD patients [1,24]. These include increased intravascular calcium phosphate deposition and coronary artery calcification, [25-27] arterial stiffness, enhanced coagulability, endothelial dysfunction, increased subclinical inflammation, [28] volume overload [29], and left ventricular remodeling and dysfunction [30,31]. In addition, patients with CKD undergoing percutaneous coronary intervention for an acute coronary syndrome have been shown to have less complete revascularization, a condition associated with a poorer prognosis [32].

Our results draw attention to the particularly high risk associated with CKD in patients with coronary artery disease. Whether or not CKD is a "coronary artery disease risk equivalent" (i.e., the risk associated with CKD in patients without coronary artery disease at baseline is equivalent to that associated with established coronary artery disease) is debated $[17,33]$, but the present study shows that in patients with established chronic coronary artery disease, CKD markedly and dose-dependently further increases the risks for total and cardiovascular mortality and cardiovascular events. This increased risk is similar to that conferred by diabetes or a systolic blood pressure $\geq 160 \mathrm{mmHg}$ for CKD stage 3a, and much higher than that of any risk factor or comorbid condition, including a history of heart failure, for CKD stage $3 \mathrm{~b}$ or more. These results obtained in patients with coronary artery disease are line with those obtained in the general population by Tonelli et al., who showed a higher cardiovascular risk in patients with eGFR $<60$ and even more so $<45 \mathrm{~mL} / \mathrm{min} / 1.73 \mathrm{~m}^{2}$ than in those with diabetes [17].

These results strongly support integrating eGFR in risk assessment and treatment targets for secondary prevention in patients with coronary artery disease. Patients with eGFR below $60 \mathrm{~mL} / \mathrm{min} / 1.73 \mathrm{~m}^{2}$ need to be monitored carefully and clinicians should attempt to optimize secondary prevention throughout follow-up. Prevention of end-stage renal disease is very important, but not the only goal in these patients who require effective cardiovascular intervention to reduce the exponential cardiovascular burden associated with decreasing eGFR. Patients are more likely to die or suffer adverse cardiovascular events than develop end-stage renal disease [12,14].

The prevalence of diabetes in our study population was 30\%. Interestingly, no interaction was found between eGFR and diabetes, for any of the studies outcomes. This is in line with the meta-analysis by Fox et al. which showed, in thirty combined general population and high-risk cohorts, that the relative increases in risks of total and cardiovascular mortality with lower eGFR were the same in patients with and without diabetes [34]. Altogether, this supports the use of similar thresholds for diagnosis and classification of CKD in the presence or absence of diabetes. It's noteworthy that patients 
with both CKD and diabetes, or at high risk for new onset diabetes, are at extremely high risk due to the combination of both conditions [35].

The analysis of eGFR as a continuous variable revealed a significant interaction between worsening renal function and a history of treated hypertension for the outcomes myocardial infarction and stroke (significant effect only in patients with hypertension). However, no interaction with hypertension was observed for the other outcomes, including cardiovascular mortality. In contrast, in the study by Mahmoodi et al. [4], the relative risk of mortality associated with a lower eGFR was stronger in non-hypertensive than hypertensive patients. Overall, the presence of CKD should be considered a relevant additional risk factor for cardiovascular mortality, irrespective of hypertension and diabetes status.

Strengths of our study include that patients were recruited from 43 countries, and treated according to routine clinical practice, with detailed and source-verified information on risk factors and comorbidities as well as outcome identification, and thereby reflect worldwide epidemiology of coronary artery disease patients, and are more generalizable than results obtained in the highly selected populations from most randomized clinical trials. These data are unique in a contemporary cohort of patients with chronic coronary artery disease and provide important data on the risk associated with CKD, versus that associated with other risks factors including diabetes, in this specific population. In addition, the large sample size allowed adjusting for multiple potential confounders, which is very important in the case of CKD patients who suffer multiple comorbidities.

Our study has several limitations. Due to restrictions preventing collection of ethnicity data in some European countries, eGFR based on the CKD-EPI equation was not available in the entire CLARIFY population. Another limitation, inherent to the nature of a registry, was that serum creatinine concentration measurement was not standardized across centres. In addition, proteinuria was not collected in the CLARIFY registry, so we could not analyze the expected even higher risk in patients with both CKD and proteinuria [3,5].

In conclusion, eGFR $<60 \mathrm{~mL} / \mathrm{min} / 1 / 73 \mathrm{~m}^{2}$ was associated with a gradually increasing risk of all-cause and cardiovascular mortality, independently of multiple potential confounders. Even moderately reduced eGFR should draw at least as much attention as well-recognized risk factors and high-risk conditions such as diabetes, uncontrolled hypertension, and previous myocardial infarction. These findings are unique in a population with chronic coronary artery disease and underscore the high cardiovascular risk associated with CKD, especially of stage 3 or more, suggesting the clinical and public health importance of identifying and treating risk factors for cardiovascular disease in these patients.

Supplementary Materials: The following are available online at http://www.mdpi.com/2077-0383/9/1/4/s1.

Author Contributions: Conceptualization, E.V.-P., P.R.K., X.G.-M., I.F., R.F., M.T., K.M.F. and P.G.S.; Formal analysis, N.G. and I.F.; Funding acquisition, K.M.F. and P.G.S.; Investigation, J.Z., R.F., M.T. and P.G.S.; Methodology, N.G., P.R.K., J.-C.T., J.Z., K.M.F. and P.G.S.; Project administration, N.G., J.-C.T., I.F., K.M.F. and P.G.S.; Software, I.F.; Supervision, J.-C.T., I.F., K.M.F. and P.G.S.; Writing-original draft, E.V.-P.; Writing-review \& editing, N.G., P.R.K., X.G.-M., J.-C.T., I.F., J.Z., R.F., M.T., K.M.F. and P.G.S. All authors have read and agreed to the published version of the manuscript.

Funding: The CLARIFY registry is supported by Servier. The sponsor had no role in the study design or data analysis and interpretation, or in the decision to submit the manuscript for publication. The sponsor assisted with the set-up, data collection, and management of the study in each country. All statistical analyses were performed at the Robertson Center for Biostatistics, University of Glasgow, UK.

Conflicts of Interest: Vidal-Petiot reports non-financial support from Servier, outside the submitted work. Greenlaw reports grants from Servier during the conduct of the study. Kalra reports personal fees from Servier, during the conduct of the study; personal fees from Abbott, AstraZeneca, Boston Scientific, Napp, Novartis, and Novo Nordisk, grants and personal fees from Vifor Pharma, grants from Pharmacosmos, outside the submitted work. Garcia-Moll reports personal fees from Servier, outside the submitted work. Tardif reports grants and personal fees from Amarin, Astra Zeneca, Dalcor, Pfizer, Sanofi and Servier and grants from Ionis and Regenex Bio, outside the submitted work; In addition, Tardif has a patent Pharmacogenomics-guided CETP inhibition issued. Ford reports grants and personal fees from Servier, during the conduct of the study; grants from Pharmacosmos, British Heart Foundation, Kidney Research UK, and Vifor Pharma, outside the submitted work. Zamorano reports 
grants from Abbott and Edwards, outside the submitted work. Ferrari reports grants and personal fees from Servier international, personal fees from Merck Serono, personal fees from Bayer, grants and personal fees from Novartis, personal fees from Pfizer, personal fees from Alphasigma, personal fees from Boeheringer Ingelheim, personal fees from Cipla, outside the submitted work. Tendera reports personal fees from Servier, during the conduct of the study; personal fees from Bayer, Cadila Pharmaceuticals, Janssen-Cilag, Kowa, PERFUSE Group, Servier, and UCB Pharmaceuticals, outside the submitted work. Fox reports personal fees and non-financial support from Servier and Broadview Ventures, personal fees from AstraZeneca, TaurX, and CellAegis, and non-financial support from Armgo, outside the submitted work. Steg reports grants and personal fees from Servier, during the conduct of the study; grants and personal fees from Bayer/Janssen, Merck Sanofi, and Amarin, personal fees from Amgen, Bristol Myers Squibb, Boehringer-Ingelheim, Pfizer, Novartis, Regeneron, Lilly, AstraZeneca, from Servier, Novo Nordisk, and Idorsia, outside the submitted work.

\section{References}

1. Go, A.S. cardiovascular disease consequences of CKD. Semin. Nephrol. 2016, 36, 293-304. [CrossRef]

2. Manjunath, G.; Tighiouart, H.; Ibrahim, H.; MacLeod, B.; Salem, D.N.; Griffith, J.L.; Coresh, J.; Levey, A.S.; Sarnak, M.J. Level of kidney function as a risk factor for atherosclerotic cardiovascular outcomes in the community. J. Am. Coll. Cardiol. 2003, 41, 47-55. [CrossRef]

3. Chronic Kidney Disease Prognosis Consortium; Matsushita, K.; van der Velde, M.; Astor, B.C.; Woodward, M.; Levey, A.S.; de Jong, P.E.; Coresh, J.; Gansevoort, R.T. Association of estimated glomerular filtration rate and albuminuria with all-cause and cardiovascular mortality in general population cohorts: A collaborative meta-analysis. Lancet 2010, 375, 2073-2081. [CrossRef]

4. Mahmoodi, B.K.; Matsushita, K.; Woodward, M.; Blankestijn, P.J.; Cirillo, M.; Ohkubo, T.; Rossing, P.; Sarnak, M.J.; Stengel, B.; Yamagishi, K.; et al. Associations of kidney disease measures with mortality and end-stage renal disease in individuals with and without hypertension: A meta-analysis. Lancet 2012, 380, 1649-1661. [CrossRef]

5. Matsushita, K.; Coresh, J.; Sang, Y.; Chalmers, J.; Fox, C.; Guallar, E.; Jafar, T.; Jassal, S.K.; Landman, G.W.D.; Muntner, P.; et al. Estimated glomerular filtration rate and albuminuria for prediction of cardiovascular outcomes: A collaborative meta-analysis of individual participant data. Lancet Diabetes Endocrinol. 2015, 3, 514-525. [CrossRef]

6. Dumaine, R.L.; Montalescot, G.; Steg, P.G.; Ohman, E.M.; Eagle, K.; Bhatt, D.L. Reach registry investigators renal function, atherothrombosis extent, and outcomes in high-risk patients. Am. Heart J. 2009, 158, 141-148. [CrossRef] [PubMed]

7. Hillege, H.L.; Nitsch, D.; Pfeffer, M.A.; Swedberg, K.; McMurray, J.J.V.; Yusuf, S.; Granger, C.B.; Michelson, E.L.; Ostergren, J.; Cornel, J.H.; et al. Renal function as a predictor of outcome in a broad spectrum of patients with heart failure. Circulation 2006, 113, 671-678. [CrossRef] [PubMed]

8. Knuuti, J.; Wijns, W.; Saraste, A.; Capodanno, D.; Barbato, E.; Funck-Brentano, C.; Prescott, E.; Storey, R.F.; Deaton, C.; Cuisset, T.; et al. 2019 ESC Guidelines for the diagnosis and management of chronic coronary syndromes. Eur. Heart J. 2019. [CrossRef] [PubMed]

9. Vidal-Petiot, E.; Ford, I.; Greenlaw, N.; Ferrari, R.; Fox, K.M.; Tardif, J.-C.; Tendera, M.; Tavazzi, L.; Bhatt, D.L.; Steg, P.G.; et al. Cardiovascular event rates and mortality according to achieved systolic and diastolic blood pressure in patients with stable coronary artery disease: An international cohort study. Lancet 2016, 388, 2142-2152. [CrossRef]

10. Sorbets, E.; Greenlaw, N.; Ferrari, R.; Ford, I.; Fox, K.M.; Tardif, J.-C.; Tendera, M.; Steg, P.G. Clarify Investigators Rationale, design, and baseline characteristics of the CLARIFY registry of outpatients with stable coronary artery disease. Clin. Cardiol. 2017, 40, 797-806. [CrossRef]

11. Levey, A.S.; Stevens, L.A.; Schmid, C.H.; Zhang, Y.L.; Castro, A.F.; Feldman, H.I.; Kusek, J.W.; Eggers, P.; Van Lente, F.; Greene, T.; et al. A new equation to estimate glomerular filtration rate. Ann. Intern. Med. 2009, 150, 604-612. [CrossRef] [PubMed]

12. Matsushita, K.; Mahmoodi, B.K.; Woodward, M.; Emberson, J.R.; Jafar, T.H.; Jee, S.H.; Polkinghorne, K.R.; Shankar, A.; Smith, D.H.; Tonelli, M.; et al. Comparison of risk prediction using the CKD-EPI equation and the MDRD study equation for estimated glomerular filtration rate. JAMA 2012, 307, 1941-1951. [CrossRef] [PubMed] 
13. Kidney Disease: Improving Global Outcomes (KDIGO) CKD Work Group. KDIGO 2012 clinical practice guideline for the evaluation and management of chronic kidney disease. Chapter 1: Definition and classification of CKD. Kidney Int. Suppl. 2013, 3, 19-62.

14. Go, A.S.; Chertow, G.M.; Fan, D.; McCulloch, C.E.; Hsu, C. Chronic kidney disease and the risks of death, cardiovascular events, and hospitalization. N. Engl. J. Med. 2004, 351, 1296-1305. [CrossRef]

15. Culleton, B.F.; Larson, M.G.; Wilson, P.W.; Evans, J.C.; Parfrey, P.S.; Levy, D. Cardiovascular disease and mortality in a community-based cohort with mild renal insufficiency. Kidney Int. 1999, 56, 2214-2219. [CrossRef]

16. Garg, A.X.; Clark, W.F.; Haynes, R.B.; House, A.A. Moderate renal insufficiency and the risk of cardiovascular mortality: Results from the NHANES I. Kidney Int. 2002, 61, 1486-1494. [CrossRef]

17. Tonelli, M.; Muntner, P.; Lloyd, A.; Manns, B.J.; Klarenbach, S.; Pannu, N.; James, M.T.; Hemmelgarn, B.R. Alberta kidney disease network risk of coronary events in people with chronic kidney disease compared with those with diabetes: A population-level cohort study. Lancet 2012, 380, 807-814. [CrossRef]

18. Malhotra, R.; Nguyen, H.A.; Benavente, O.; Mete, M.; Howard, B.V.; Mant, J.; Odden, M.C.; Peralta, C.A.; Cheung, A.K.; Nadkarni, G.N.; et al. Association between more intensive vs. less intensive blood pressure lowering and risk of mortality in chronic kidney disease stages 3 to 5: A systematic review and meta-analysis. JAMA Intern. Med. 2017, 177, 1498-1505. [CrossRef]

19. Hsu, H.-H.; Kor, C.-T.; Hsieh, Y.-P.; Chiu, P.-F. Effects of prevalent and incident atrial fibrillation on renal outcome, cardiovascular events, and mortality in patients with chronic kidney disease. J. Clin. Med. 2019, 8, 1378. [CrossRef]

20. Lee, W.-C.; Lee, Y.-T.; Li, L.-C.; Ng, H.-Y.; Kuo, W.-H.; Lin, P.-T.; Liao, Y.-C.; Chiou, T.T.-Y.; Lee, C.-T. The number of comorbidities predicts renal outcomes in patients with stage 3-5 chronic kidney disease. J. Clin. Med. 2018, 7, 493. [CrossRef]

21. Pecoits-Filho, R.; Fliser, D.; Tu, C.; Zee, J.; Bieber, B.; Wong, M.M.Y.; Port, F.; Combe, C.; Lopes, A.A.; Reichel, H.; et al. Prescription of renin-angiotensin-aldosterone system inhibitors (RAASi) and its determinants in patients with advanced CKD under nephrologist care. J. Clin. Hypertens. 2019, 21, 991-1001. [CrossRef] [PubMed]

22. Koutroumpakis, E.; Gosmanova, E.O.; Stahura, H.; Jou, S.; Alreshq, R.; Ata, A.; Sidhu, M.S.; Philbin, E.; Boden, W.E.; Lyubarova, R. Attainment of guideline-directed medical treatment in stable ischemic heart disease patients with and without chronic kidney disease. Cardiovasc. Drugs Ther. 2019, 33, 443-451. [CrossRef] [PubMed]

23. Ferro, C.J.; Mark, P.B.; Kanbay, M.; Sarafidis, P.; Heine, G.H.; Rossignol, P.; Massy, Z.A.; Mallamaci, F.; Valdivielso, J.M.; Malyszko, J.; et al. Lipid management in patients with chronic kidney disease. Nat. Rev. Nephrol. 2018, 14, 727-749. [CrossRef] [PubMed]

24. Parfrey, P.S.; Foley, R.N. The clinical epidemiology of cardiac disease in chronic renal failure. J. Am. Soc. Nephrol. 1999, 10, 1606-1615. [PubMed]

25. Raggi, P.; Boulay, A.; Chasan-Taber, S.; Amin, N.; Dillon, M.; Burke, S.K.; Chertow, G.M. Cardiac calcification in adult hemodialysis patients. A link between end-stage renal disease and cardiovascular disease? J. Am. Coll. Cardiol. 2002, 39, 695-701. [CrossRef]

26. Cano-Megías, M.; Guisado-Vasco, P.; Bouarich, H.; de Arriba-de la Fuente, G.; de Sequera-Ortiz, P.; Álvarez-Sanz, C.; Rodríguez-Puyol, D. Coronary calcification as a predictor of cardiovascular mortality in advanced chronic kidney disease: A prospective long-term follow-up study. BMC Nephrol. 2019, 20, 188. [CrossRef]

27. Wang, X.-R.; Zhang, J.-J.; Xu, X.-X.; Wu, Y.-G. Prevalence of coronary artery calcification and its association with mortality, cardiovascular events in patients with chronic kidney disease: A systematic review and meta-analysis. Ren. Fail. 2019, 41, 244-256. [CrossRef]

28. Shlipak, M.G.; Fried, L.F.; Crump, C.; Bleyer, A.J.; Manolio, T.A.; Tracy, R.P.; Furberg, C.D.; Psaty, B.M. Elevations of inflammatory and procoagulant biomarkers in elderly persons with renal insufficiency. Circulation 2003, 107, 87-92. [CrossRef]

29. Faucon, A.-L.; Flamant, M.; Metzger, M.; Boffa, J.-J.; Haymann, J.-P.; Houillier, P.; Thervet, E.; Vrtovsnik, F.; Stengel, B.; Geri, G.; et al. Extracellular fluid volume is associated with incident end-stage kidney disease and mortality in patients with chronic kidney disease. Kidney Int. 2019, 96, 1020-1029. [CrossRef] 
30. Bansal, N.; Zelnick, L.; Bhat, Z.; Dobre, M.; He, J.; Lash, J.; Jaar, B.; Mehta, R.; Raj, D.; Rincon-Choles, H.; et al. Burden and Outcomes of Heart Failure Hospitalizations in Adults With Chronic Kidney Disease. J. Am. Coll. Cardiol. 2019, 73, 2691-2700. [CrossRef]

31. Izumaru, K.; Hata, J.; Nakano, T.; Nakashima, Y.; Nagata, M.; Fukuhara, M.; Oda, Y.; Kitazono, T.; Ninomiya, T. Reduced Estimated GFR and Cardiac Remodeling: A Population-Based Autopsy Study. Am. J. Kidney Dis. 2019, 74, 373-381. [CrossRef] [PubMed]

32. Cardi, T.; Kayali, A.; Trimaille, A.; Marchandot, B.; Ristorto, J.; Hoang, V.A.; Hess, S.; Kibler, M.; Jesel, L.; Ohlmann, P.; et al. Prognostic value of incomplete revascularization after percutaneous coronary intervention following acute coronary syndrome: Focus on CKD patients. J. Clin. Med. 2019, 8, 810. [CrossRef] [PubMed]

33. Parikh, N.I.; Hwang, S.-J.; Larson, M.G.; Levy, D.; Fox, C.S. Chronic kidney disease as a predictor of cardiovascular disease (from the Framingham Heart Study). Am. J. Cardiol. 2008, 102, 47-53. [CrossRef] [PubMed]

34. Fox, C.S.; Matsushita, K.; Woodward, M.; Bilo, H.J.G.; Chalmers, J.; Heerspink, H.J.L.; Lee, B.J.; Perkins, R.M.; Rossing, P.; Sairenchi, T.; et al. Associations of kidney disease measures with mortality and end-stage renal disease in individuals with and without diabetes: A meta-analysis. Lancet 2012, 380, 1662-1673. [CrossRef]

35. Hsu, P.-K.; Kor, C.-T.; Hsieh, Y.-P. Effect of new-onset diabetes mellitus on renal outcomes and mortality in patients with chronic kidney disease. J. Clin. Med. 2018, 7, 550. [CrossRef]

(C) 2019 by the authors. Licensee MDPI, Basel, Switzerland. This article is an open access article distributed under the terms and conditions of the Creative Commons Attribution (CC BY) license (http://creativecommons.org/licenses/by/4.0/). 